\title{
Cognitive Modeling of the Diversified Rural Economy Development in the Context of Digitalization
}

\author{
Zakshevskii V.G.* \\ Director of Institute Scientific-Research Institute of \\ Economics and Organization of Agro-Industrial Complex of \\ the Central Black Earth region of the Russian Federation \\ Voronezh, Russian \\ e-mail:vgzak@bk.ru
}

\section{Merenkova I.N.}

Head of the Department of Administration of the AIC and Rural Territories

Scientific-Research Institute of Economics and Organization of Agro-Industrial Complex of the Central

Black Earth region of the Russian Federation

Voronezh, Russia

e-mail: upr-nii@yandex.ru

\section{Novikova I.I.}

Leading Research Associate of the Department of Administration of the AIC and Rural Territories Scientific-Research Institute of Economics and Organization of Agro-Industrial Complex of the Central

Black Earth region of the Russian Federation

Voronezh, Russia

e-mail: irinchic@mail.ru

\author{
Kusmagambetova E.S. \\ Senior Research Associate of the Department of \\ Administration of the AIC and Rural Territories \\ Scientific-Research Institute of Economics and \\ Organization of Agro-Industrial Complex of the Central \\ Black Earth region of the Russian Federation \\ Voronezh, Russia \\ e-mail: eskus@bk.ru
}

\section{Gavrilova Z.V.}

Leading Research Associate of the Department of Administration of the AIC and Rural Territories Scientific-Research Institute of Economics and Organization of Agro-Industrial Complex of the Central Black Earth region of the Russian Federation Voronezh, Russia e-mail: zoya0203@yandex.ru

\section{Parkhomov E.A.}

Applicant of the Federal State Budgetary Educational Institution of Higher Education "Belgorod State Agricultural University named after V. Gorin"

Belgorod, Russia e-mail: parhomov@belapk.ru

you to form its profile patterns. The functional and structural block includes the structure, functions and factors affecting the diversified development of rural areas. The object-subject block that contains the object subsystem (a set of economic entities, population, resources, infrastructure) and the subject subsystem (institutional structures - organizational and formal institutions). The cognitive block of the model includes both theoretical and methodological basis for the study of diversified rural development. The use of the above approach results in the obtaining the emergent effect due to the implementation of target settings within each functional special purpose cycle.

Keywords - rural areas, diversification, rural economies, cognitive modeling, model, digitalization.

\section{INTRODUCTION}

The current social development is characterized by the global transformation caused by the mainstreaming of digital technologies.

The Russian economy is undergoing tremendous changes at all levels of its functioning including the micro-level (individual organizations), the mesoscale (municipalities, 
including rural settlements; regions; macroregions) and the macro level (state) in the context of digitalization. These changes can lead to both positive effects (increasing the availability of advanced knowledge; expanding opportunities for training and retraining of the population, improvement of existing products and services and the emergence of new ones; capacity building to enhance the effectiveness of the implementation of innovative ideas in the social sphere, the growth level of the economy and so on. etc.) and negative (increase in the number of unemployed people;. aggravation of social inequality, the depletion layer of the middle class). Having devastating negative consequences of digitization may occur in rural areas, jeopardizing the possibility of continued effective functioning of the rural economy, which is currently just beyond the path of diversified development and in need of the full support of this process [1-3].

There is an obvious need for the transformation of knowledge about the diversified development of the rural economy and its presentation in a form considering the modern realities of the digital economy in order to achieve a deeper understanding of the processes.

Study of the problems of the diversified development of rural areas requires to carry out the integrated economic analysis of both internal and external factors affecting the diversification potential and the possibility of organizing new kinds of activities. The practical realization of the obtained results should be carried out by using the appropriate tools, i.e. cognitive technologies applied when studying and modeling complex economic and social systems $[4,5]$.

Therefore, building a model of diversified rural development is a process of formalization of knowledge obtained at the stage of cognitive structuring, taking into account the specifics of rural areas. In this regard, the proposed model should contain system characteristics and has to be presented as a set of elements ensuring the integrity of the system, on the one hand, and the achievement of the set goals of modeling on the other hand.

\section{LITERATURE REVIEW}

Rural territories, being spatial territorial entities, is viewed as a complex socio-economic system, including multifunctional and interconnected social, economic and environmental blocks that is meant to be the basis for determining the necessary conditions for rural diversification, i.e. stimulate diverse activities [6]. On this basis, it is necessary to use the appropriate tools to model the development of a diversified rural economy [7, 8].

It is important to bear in mind that in most cases the model is a kind of a simplified version of the description of reality that allows us to show the most important points, but in a compressed compact form. Considering this approach, the rural development models can be divided into two groups on the base of their construction. The first group fully reproduces the objective reality formed under the influence of market laws and laws. The second group subsequently becomes the basis for creating the necessary managerial tools for all levels of government.
Informal models are sectoral, redistributive and territorial, which, in turn, are consistent with the basic concepts of rural development.

Thus, the sectoral model is built on the base of the concept according to which the agrarian sector plays the significant role in the economy. Therefore it is thought that only progress in the development of the agricultural sector will lead to the development of rural areas.

The redistribution model is based on the concept of narrowing the gap between depressed and developed rural areas due to the more effective overflow of financial support funds, which can be either in the form of direct compensation concentrated on the immediate neutralization of negative factors, or in the form of grants for restructuring the rural economy.

The basis of the territorial model is the concept of rural development, the implementation of which is directly related to the integrated and effective use of the available natural resource potential with the simultaneous introduction of advanced types of production at the local level [9]

When developing a model of diversified development of the rural economy, it should be taken into account that, in general, the sectoral model of rural development is being implemented in the country, which is considered to be imperfect and of low effectiveness. This is primarily due to the multi-directional key strategic goals of agrarian policy, namely conflicting budget financing, the distribution of land resources, the concentration of production. Therefore, the reorientation of the sectoral model to the territorial one is necessary considering the gradual transition from the monofunctional model of the rural economy to the multifunctional one based on the social approach and taking into account the natural, manufacturing and resourcing features of rural areas.

Cognitive modeling is used to gain better understanding of the multifunctional model of the rural economy and to obtain the theoretical basis for the diversified rural development.

F. Roberts is recognized as the founder of the method of cognitive modeling. Considering his ideas the cognitiveness is viewed not only as the knowledge of the objects and processes of research, but also as the assumptions, subjects and processes of its formation. This notion allowed the authors to propose a cognitive model of diversified rural development. The methodological foundations of cognitive modeling developed by R. Axelrod, including the methodology for structuring the situation under study and the methods for analyzing the situation directly is the theoretical basis of the model [10].

This methodology allows a clear interpretation of new knowledge related to the subject of the study - the diversified development of rural economies in modern conditions since it involves the use of a variety of cognitive tools.

\section{RESULTS}

The proposed cognitive model highlights the system-based cause-and-effect sequence "goals - functions - structure - 
functioning - result" considering the business cycle of negative impacts and special aspects of reaction stratified by economic levels. It is based on the dynamic unity of the operation processes of its components under the influence of the external environment, which allows you to form its profile patterns $[11,12]$.

The study of the existing approaches to the problem of diversification resulted in the developing of the author's approach, implemented in the form of a cognitive model of diversified development of rural areas, including three main blocks, which is reflected in Figure 1:

- a functional and structural block composed of the main structural modules: structure, functions of the rural areas and the factors affecting their diversification;
- an object-subject block that contains both an object subsystem (a set of economic entities, population, resources, infrastructure) and a subject subsystem (institutional structures - organizational and formal institutions);

- a cognitive block - as a theoretical and methodological basis for the knowledge of diversified rural development, combining interfacing modules in the form of an algorithm for systemic-functional targeted and functional-structural research [13].

The natural environment and society are considered to be the important factors in the cognitive model, including a complex of resources and needs, which is an economic rationale for the formation of rural diversification and the determination of directions and ways of its development.

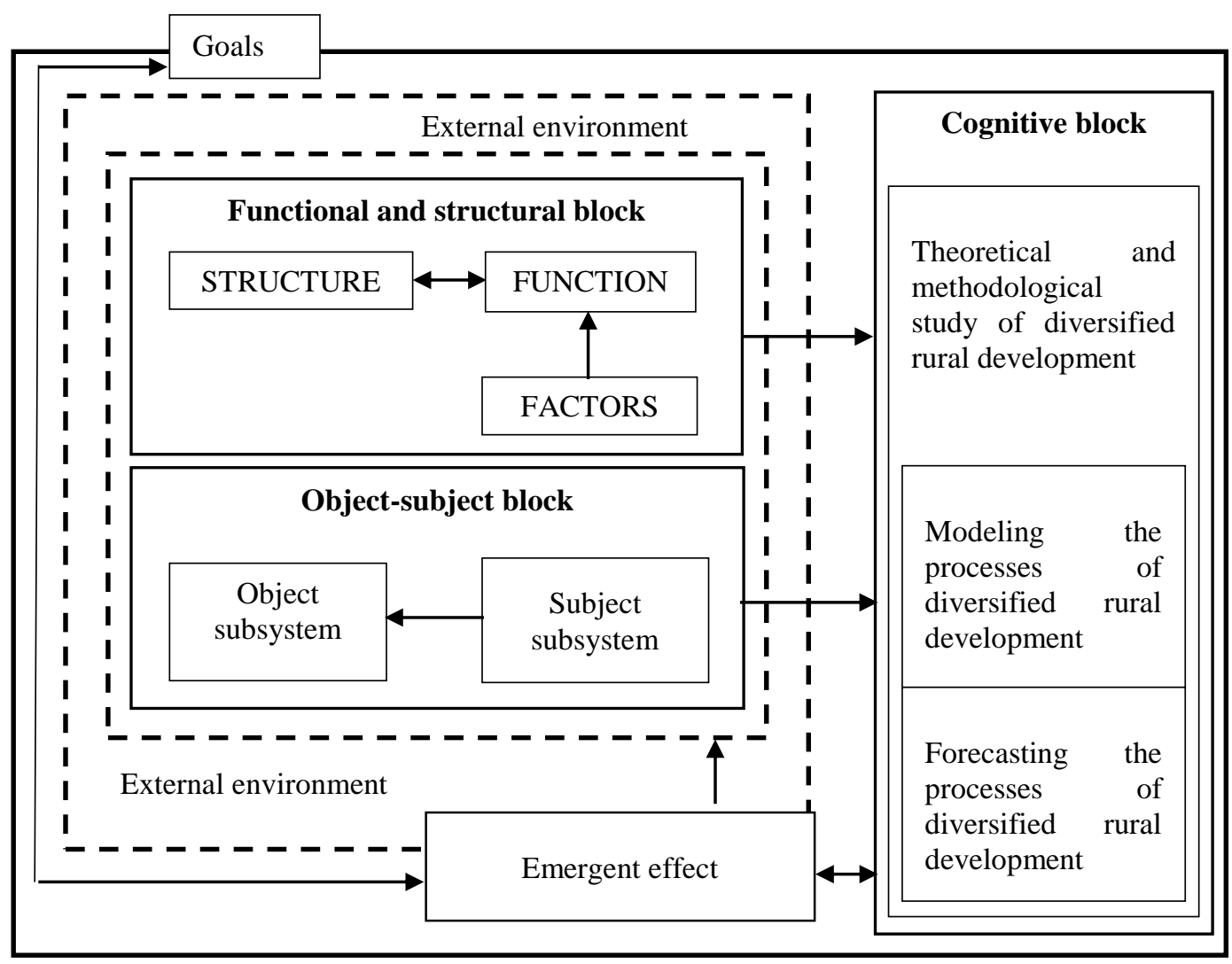

Fig. 1. Cognitive model of diversified rural development

Nature is viewed as one of the factors of the model and is determined as a natural habitat, i.e. a combination of edaphicclimatic zone and other natural conditions, which allows them to be used for the both direct and indirect consumption, the maintaining of the way of living and the life quality improvement of countrymen.

Socium is a particular system of the social environment of a country dweller, providing the interaction of citizens, family, public organizations and the state. In rural areas, society is often related to the rural community (an association of rural residents and organizations operating in different spheres of life), which perpetuate itself within the conditions of the natural landscape and social environment by attracting economic, human, communication and other resources [14].

The functional and structural block includes the structure, functions and factors affecting the diversified development of rural areas. The following theoretical and methodological principles have been taken into account while forming this block on the basis of the functional-structural targeted approach: "the functions of the rural territories that are being implemented determine the structure of the economy; different structures can put into practice the same functions; the environment changes result into the functions changes of rural 
areas, respectively, ensuring the structure changes leading to its diversification".

The application of the above-mentioned approach results in the emergent effect due to the implementation of targets within each functional target cycle. The emergence effect, which includes natural, social and economic components, is expressed in the effectiveness of diversification [15].

The object-subject block combines two subsystems: the object and the subject.

The object subsystem of the model is represented by a set of economic entities; population (its age and sex structure, resettlement, income, etc.); resources of the territory (natural, land, labor, financial, etc.); rural infrastructure (social, industrial, transport, engineering) within rural municipalities.

The central element of the object subsystem of the diversified rural development model is the population that is heterogeneous in age, level of education and professional training. On the one hand, rural residents are the main labor force for economic entities, on the other hand, they are consumers of goods and services produced and provided in rural areas, and, thirdly, they are users of rural resources.

Economic entities (organizations of various sectors of the economy, individual entrepreneurs, agricultural consumer cooperatives, agricultural holdings, groups of companies, etc.) include in the production process various resources of rural areas, provide jobs as well as income for the countrymen, create gross added value, ensure tax payments to the federal, regional and municipal budgets. However, they can also have a negative impact on the state of the rural environment, and under the influence of market laws and the policies of government bodies, they can stagnate or degrade.

The resources include not only those already involved in the processes of production and social development, but also those that can be used to grow the rural economy. All natural resources in rural areas perform the environment-forming function, and they must be considered when choosing a diversification method. At the same time, the socio-economic resources can be considered as adjustable and controlled system of the state of a rural territory in order to achieve the objective function of its development and diversification.

The social and engineering infrastructure that ensures the effective functioning of all institutions of the social sphere in order to meet the diverse needs of rural residents play the important role in the system of factors influencing the diversification of the rural economy. Rural infrastructure is a set of economic real-valued elements or industries that create general conditions for the development of socio-economic processes in rural areas and, ultimately, focused on reproduction, life support, mode of life and activities of the rural population, its physical, intellectual and spiritual development.

The set of relationships between rural residents, business entities, organizations of all types, based on the use of natural resource potential, determine the way of life of people in rural areas.
Considering the subjective subsystem of the model, it should be understood that it has a multi-level hierarchical structure. There are institutional structures - organizational and formal institutions (legal documents of federal importance), focused on the formulation and implementation of State policy and regulatory framework in the field of rural development at the macro level. The implementation of federal State policy and legal regulation in the development of rural areas of the respective republics, territories and regions is realized by the similar institutional structures taking into account regional specifics at the regional level. Local governments are viewed as the main organizational structures at the municipal level. Whereas legal acts of municipal districts and rural settlements (standing orders; decisions of councils of deputies; municipal council's decisions) are considered to be formal institutions.

The object subsystem is characterized by the complex diversity of its elements. Consequently, a set of norms and rules as the formal institutions (acts, government decrees, concepts, programs and other regulatory documents) should be implemented considering the agrarian policy objectives in order to determine the way of budget support and other parameters of the model.

The cognitive block of the model includes a theoretical and methodological basis for the study of diversified rural development. The information-analytical component of the cognitive model combines the two modules, i.e. "Modeling of the processes of diversified development" and "Prediction of the processes of diversified development", ensuring the formation of the parameters of the required emergent effect for the rural areas.

\section{CONCLUSION}

Thus, in the modern world economy there is a certain tendency for countries to enter the new stage of the development through the introduction of digitalization elements. This process has not only positive, but also negative consequences, which are mostly pronounced in the rural economy, which is moving towards the diversified development.

The knowledge about the diversified development of the rural economy is presented in accordance with the modern digitalization context in order to gain better understanding of the changes taking place and to ensure its modeling.

The proposed cognitive model of diversified development of rural areas is based on the systemic and functionalstructural targeted approaches and highlights the system-based cause-and-effect sequence "goals - functions - structure functioning - result", which allows you to form its profile patterns.

The model includes the three important blocks. Модель включает три важных блока. The functional and structural block composes of the main structural modules: structure, functions of the rural areas and the factors affecting their diversification. The object-subject block contains two blocks: the object subsystem (a set of economic entities, population, resources, infrastructure) and the subject subsystem 
(institutional structures - organizational and formal institutions). The cognitive block includes the theoretical and the methodological basis for the knowledge of diversified rural development. The external environment is singled out as the factor in the model representing by nature and society and is viewed as the essential condition for the formation of rural diversification, as well as determining the directions and ways of its development. The emergent effect is proposed as the important module in the model. It is pointed out that the emergent effect includes natural, social and economic elements and reflects the effectiveness of diversification.

\section{References}

[1] R.U. Gusmanov, A.R. Kuznetsova, E.V. Stovba, M.R. Avzalov, "Newparadigm of the economic development of the regional rural territories", European Proceedings of Social and Behavioural Sciences, vol. 59, pp. 206-217, December 2019 [Int. Sci. and Pract. Conf. on Contemporary Issues of Economic Development of Russia - Challenges and Opportunities (CIEDR), 1083 p., 2019].

[2] E.N. Klochko, M.V. Zelinskaya, "Ethno-economy in terms of digitalization of Russia", Modern management trends and the digital economy: from regional development to global economic growth (MTDE 2019), vol. 81, pp. 210-213, April 2019 [1st Int. Sci. Conf. on Modern Management Trends and the Digital Economy - From Regional Development to Global Economic Growth (MTDE), 813 p., 2019].

[3] M.A. Afonasova, E.E. Panfilova, M.A. Galichkina, B. Slusarczyk, "Digitalization in economy and innovation: the effect on social and economic processes", Polish J. of manag.t studies, vol. 19, no. 2, pp. 22-32, June 2019.

[4] L. Christiaensen, "Introduction: rural diversification, secondary towns and poverty reduction: do not miss the middle", Agricult.economics, vol. 44, no. 4-5, pp. 433-434, July 2013.

[5] V.G. Zakshevskii, I.N. Merenkova, I.I. Novikova, E.S. Kusmagambetova "Methodological Toolkit for Diagnosing Diversification of Rural Economy", Ekonomika regiona [Economy of Region], vol. 15, no. 2, pp. 520-533, June 2019.

[6] N.A. Serebryakova, I.V. Avdeev, "The content of structural transformations of the region's economy, adequate to the requirements of digitalization", Proc. of the Voronezh State Univer. of Engineer. Technol., vol. 80, no. 4, pp. 408-412, December 2018.

[7] L. Kalachevska, "Models for innovation development of rural territories based on infrastructure development", Baltic J. of econ. studies, vol. 4 , no. 1, pp. 175-180, March 2018.

[8] G. Salchner, "Design of territories and management structures in regional and rural development", New challenges of economic and business development - 2017: digital economy, pp. 531-542, May 2017 [9th Int. Sci. Conf. on New Challenges of Economic and Business Development - Digital Economy, 787 p., 2017].

[9] I. Merenkova, O. Smyslova, A. Kokoreva "Development models of rural areas: theoretical approaches and formation specificity", IOP Conf. Ser. Earth and Environmental Sci., vol. 341, p. 012017, November 2019.

[10] A.A. Kulinich, "Contingency, cognitive and semiotic approaches to decision-making in the organizations", Open ed., vol. 20, no. 6, pp. 9-17, December 2016.

[11] R.J. Freund, "Cognitive Computing and Managing Complexity in Open Innovation Model", Managing Complexityб Springer Proceedings in Business and Economics, pp. 249-262, October 2015 [8th World Conf. on Mass Customization, Personalization, and Co-Creation (MCPC), 468 p., 2017]

[12] N. Leonova, "Cognitive modeling and multi criteria decision making in macroeconomic analysis", Economic and Social development, pp. 174-181, April 2014 [5th Int. Sci. Conf. on Economic and Social Development (ESD), 2nd Eastern European ESD-Conf. on Social Responsibility, 608 p., 2014].

[13] E.F. Rosenbaum, "Culture, cognitive models, and the performance of institutions in transformation countries", J. of econ. issues, vol. 35, no. 4, pp. 889-909, December 2001.

[14] G. Degli Antoni, L. Sacconi, Modeling Cognitive Social Capital and Corporate Social Responsibility as Preconditions for Sustainable Networks of Relations, chapter in Social capital, corporate social responsibility, economic behaviour and performance, Basingstoke: Palgrave, 2011, pp. 161-239.

[15] O.O. Lukina, V.V. Dudchak, "Generalized indicator and classification structures of the capital of the industrial enterprises", Proc. of the Voronezh State Univer. of Engineer. Technol., vol. 80, no. 3, pp. 423-428, September 2018. 